al, but also actually fun to use. These packages were developed at the University of Washington Department of Anesthesiology. They offer five programs for Windows and Macintosh systems, the best-known is called anesthesia simulator and at the time of writing was in its third release. Critical incidents supported in this program include anaphylaxis, cardiac arrest, latex allergy, pneumothorax, renal failure and much more. The ACLS simulation package is an interactive teaching and testing program that helps you learn and review the latest ACLS guidelines. It contains algorithms, medications, and dosages from the American Heart Association guidelines published in the 1997 Textbook of Advanced Cardiac Life Support. One is required to interpret electrocardiogram traces, defibrillate, intubate and so on. The 28 simulated cases presented in the package cover asystole, ventricular fibrillation, ventricular tachycardia, atrial fibrillation, atrial flutter, pulseless electrical activity, heart blocks and more. An expert system included in the package for teacher management in shows you what went wrong and what to do next. It can even take over the case for you if you get tired or frustrated. Finally the system provides tutorials on rhythm recognition and treatment as well as tutorials on cardiac medications.

The Critical Care Simulator offers 20 different critically ill patients for whom you must manage the airway, ventilation, fluids, and drugs to improve the patient's condition. Also available is a hemodynamics simulator, intended to improve your management of cardiovascular instability, and a sedation simulator, designed to improve your management of conscious sedation.

Of interest to many are the CME credits (provided by the University of Washington School of Medicine) that may be earned using these simulators.

Anesoft Corp. www.anesoft.com Phone: 425-6439388; Fax: 425-642-0092.

D. John Doyle MD PHD FRCPC

Toronto, Ontario

\section{Potential dangers of the paperless hospital record}

My hospital, like thousands of others, is moving towards a paperless medical record. When I recently could not find important medical information in the paper chart of one of my patients, I was told (by the "authorities") to look it up on the computer, that the paper record was on its way out, and is no longer a hospital priority.

I now envision each new batch of interns and residents having to learn to use a drawing program, or worse, a scanning program, just to make a quick sketch of an operation or to draw a quick picture of a skin rash.

More important though, when the computer network is "down" or even just quite sluggish (hardly a rare occurrence where I work), it is important to think about the kinds of clinical information one can still obtain in a hurry should something clinically untoward (like a seizure) suddenly happen to the patient. Or, imagine the surgeon who wants to recheck the MRI image series before proceeding further in a difficult operation, only to find that the network is too slow to be useful.

In a cardiac arrest setting (we average about one a day), it is particularly important that the resuscitation team leader be able to develop a treatment plan quickly with no prior familiarity with the patient. If accessing the required information requires an endless series of menu selections on a sometimes overloaded network, it is not hard to see how it might be quicker to thumb through the paper record manually.

Should there be requirements (by hospital policy or by accreditation agencies) for a minimal paper chart that at least documents the basics, such as diseases, medications and allergies?

D. John Doyle MD PHD FRCPC

Toronto, Ontario

\section{Oyston special selection}

Audio Digest

http://www.andio-digest.com/

Many readers of this Journal will already be familiar with the Audio Digest tapes. These are recordings of excellent speakers summarizing topical issues in anesthesia (and other medical specialties). They are especially suitable for listening to during long commutes or when too tired to read a journal or surf the net. It is also possible to complete a short test for CME credits. The organization has a Web site that allows one to order individual tapes or to subscribe to the series. There is an excellent search facility which allows one to find tapes on particular subjects, or one can use the chronological index. A major benefit of the site is the abstracted summary of each lecture. While these are presumably intended to whet one's appetite for the tape of the whole lecture, they cover the main points in brief note format and are useful for revision of topics. They also contain an extensive list of references.

John Oyston MB FRCPC

Scarborough, Ontario 